\title{
Função Quadrática e Lançamento Oblíquo: proposta de uma abordagem investigativa
}

\author{
Quadratic Function and Oblique launch: proposal of an investigative \\ approach
}

\author{
Wellington da Silva (wellington.silva@ifsp.edu.br) \\ (Instituto Federal de São Paulo, Departamento de Matemática)
}

\author{
Alice Assis (alice.assis@unesp.br) \\ (Universidade Estadual Paulista - Faculdade de Engenharia de Guaratinguetá, Departamento de Física)
}

Silmar Antonio Travain (silmar.travain@unesp.br)

(Universidade Estadual Paulista - Faculdade de Engenharia de Guaratinguetá, Departamento de Física)

\begin{abstract}
Resumo: Este trabalho corresponde a uma proposta de utilização de uma atividade experimental para abordar os conteúdos de função quadrática e lançamento oblíquo de forma investigativa com intuito de facilitar a abordagem de conceitos e despertar o interesse do aluno para o conteúdo, capacitando-o a formular e compreender a teoria fundamentado em uma situação real. Para isso, propõe-se a utilização de materiais de baixo custo para a construção de um minifoguete e de recursos tecnológicos, como o software GeoGebra, para analisar e embasar as discussões sobre a trajetória desse minifoguete, bem como os conceitos físicos e matemáticos envolvidos. Esta proposta pode ser aplicada com estudantes de Ensino Médio, devendo ser desenvolvida antes de qualquer discussão a respeito de função quadrática, pois espera-se que os alunos desenvolvam o conteúdo de forma investigativa embasados em suas observações e indagações coletivas, uma vez que terão, inicialmente, um único desafio: fazer com que o minifoguete obtenha o maior alcance horizontal. A partir da observação e discussão desse experimento, é possível validar algumas propriedades e conceitos, levar o aluno a perceber a teoria e articulá-la com o cotidiano, além de possibilitar a formalização matemática que, muitas vezes, parece abstrata.
\end{abstract}

Palavras-chave: Ensino de matemática; abordagem investigativa; GeoGebra.

Abstract: This paper presents a proposal of using an experimental activity to approach the quadratic function and oblique launch contents in an investigative way in order to facilitate the approach of concepts, arouse the interesting of the student about the content, empowering him to formulate and understand theory based on a real situation. For this, it is proposed the use of low-cost materials for the construction of a minirocket and technological resources such as GeoGebra software to analyze and support the discussions about the mini-rocket's trajectory, as well as the physical and mathematical concepts involved. This proposal can be applied to high school students and should be developed preceding any discussion of quadratic function for the students development content in an investigative manner based on their observations and collective inquiries, once they will have just one challenge: to lead the mini-rocket to the longest horizontal launch. From the observation and discussion of this experiment it is possible to validate some properties and concepts, to prompt the student to understand 
the theory and articulate it with daily life and enable the mathematical formalization that often seems abstract.

Keywords: Mathematics teaching; Investigative approach; GeoGebra.

\section{INTRODUÇÃO}

A necessidade de superação de um ensino de matemática pautado em resoluções de exercícios de forma mecânica e descontextualizada é eminente, considerando-se que muitos alunos têm rejeição à matemática, apresentando "uma pré-disposição negativa" (SANTOS, 2017, p. 7458) relativa a essa disciplina. Essa autora sugere que tal rejeição pode ser influenciada pelo modo como os conteúdos são abordados. Nessa perspectiva, no presente trabalho, sugerimos o uso de uma atividade experimental investigativa para abordar função quadrática.

De acordo com o Ministério da Educação (MEC), a Base Nacional Comum Curricular (BNCC) tem como proposta trazer um currículo inovador para os Ensinos Fundamental e Médio. Tal proposta enfatiza a importância de se propiciar ao aluno o questionamento e a investigação e a não aceitação das ideias prontas, atuando como um sujeito ativo em sala de aula (BRASIL, 2017).

Nessa perspectiva, Batista e Silva (2018) consideram que o ensino mediante uma abordagem investigativa é capaz de desenvolver nos alunos "competências pertinentes ao fazer científico e também competências de caráter geral como leitura, reflexão, argumentação, entre outras." (Batista e Silva, 2018, p.98). Tal abordagem consiste em introduzir o problema a ser resolvido aos alunos de modo a favorecer a elaboração de hipóteses, ideias, debates, reflexões e argumentações entre eles.

Segundo Borges (2002), a abordagem investigativa pode se apresentar em diferentes níveis, de modo que

No nível 0, o qual corresponde aproximadamente ao extremo de problema fechado, são dados o problema, os procedimentos e aquilo que se deseja observar/verificar, ficando a cargo dos estudantes coletar dados e confirmar ou não as conclusões. No nível 1 , o problema e procedimentos são definidos pelo professor, através de um roteiro, por exemplo. Ao estudante cabe coletar os dados indicados e obter as conclusões. No nível 2, apenas a situaçãoproblema é dada, ficando para o estudante decidir como e que dados coletar, fazer as medições requeridas e obter conclusões a partir deles. Finalmente, no nível 3 o nível mais aberto de investigação o estudante deve fazer tudo, desde a formulação do problema até chegar às conclusões. 
O autor destaca que atividades mais abertas, caracterizadas no nível 3, podem ser muito complexas para alunos que não têm conhecimentos sobre o conteúdo e novatos em relação ao trabalho em laboratório. Porém, afirma ter evidências de que, mesmo com essas características, esses alunos "conseguem formular problemas mais simples e planejar a sua solução em laboratório.” (BORGES, 2002, p. 306).

De qualquer modo, seja qual for o grau de abertura da atividade, o importante é que o aluno seja desafiado a resolver o problema, em um ambiente favorável à discussão, sentindo-se à vontade para propor soluções.

Nesse contexto, consideramos que o uso de atividades experimentais mediante uma abordagem investigativa pode propiciar o interesse dos alunos e, com isso, facilitar a aprendizagem. Toledo e Ferreira (2016, p. 108) consideram que

\begin{abstract}
A atividade experimental pode ser um excelente recurso para motivar e ampliar o espectro de aprendizagem, mas para isso deve trazer consigo mais do que cores e transformações espetaculosas, deve auxiliar o aluno a assumir seu papel de agente do próprio aprendizado estimulando a autonomia, a reflexão, e o senso crítico. A metodologia investigativa é consensualmente a mais indicada, resultando em um maior ganho em habilidades procedimentais e cognitivas por exigir que o aluno a partir de uma situação problema elabore uma hipótese, planeje uma metodologia, obtenha dados e os coloque sob julgamento, confirmando-a ou rejeitando-a.
\end{abstract}

$\mathrm{O}$ uso de atividades experimentais nessa perspectiva pode facilitar a aprendizagem dos conteúdos. No entanto, é fundamental que o professor permita que os alunos levantem hipóteses, defendam pontos de vista e construam novos conceitos. Segundo Almeida (1996, p.162),

O professor tem um importante papel como agente promotor do processo de aprendizagem do aluno, que constrói o conhecimento num ambiente que o desafia e o motiva para a exploração, a reflexão, a depuração de ideias e a descoberta de novos conceitos.

Outro recurso importante que apontamos é o tecnológico, mais especificamente o uso de softwares interativos. Tal recurso pode contribuir para tornar as aulas de matemática mais interessantes, despertando o interesse do aluno pelos conteúdos abordados. Entre esses softwares, destacamos o GeoGebra, por ser gratuito. Criado por Markus Hohenwartes, em 2001, o software GeoGebra "reúne recursos de geometria, álgebra e cálculo, permitindo construções geométricas de forma dinâmica e interativa e possibilitando uma postura investigativa." (ORZECHOWSKI; LOPES, 2016).

Para Fornaziere e Lübeck (2012), esse software pode ser usado tanto no ensino básico, quanto no superior, permitindo que professor e alunos desenvolvam atividades 
relativas a diversas áreas da matemática, tais como geometria, álgebra, cálculo, estatística, permitindo ainda a construção de gráficos.

Segundo Gravina (1996), esse aplicativo pode ser considerado uma ferramenta de construção, em que são elaborados desenhos de objetos e configurações geométricas a partir das propriedades que os definem e, por meio

\begin{abstract}
de deslocamentos aplicados aos elementos que compõe o desenho, este se transforma, mantendo as relações geométricas que caracterizam a situação. Assim, para um dado objeto ou propriedade, temos associada uma coleção de "desenhos em movimento", e os invariantes que aí aparecem correspondem as propriedades geométricas intrínsecas ao problema. E este é o recurso didático importante oferecido: a variedade de desenhos estabelece harmonia entre os aspectos conceituais e figurais; configurações geométricas clássicas passam a ter multiplicidade de representações; propriedades geométricas são descobertas a partir dos invariantes no movimento. (p. 6)
\end{abstract}

$\mathrm{Na}$ presente proposta, sugerimos a utilização de uma atividade experimental de cunho investigativo, de nível 2 (BORGES, 2002), para abordar função quadrática e lançamento oblíquo, utilizando o recurso de GeoGebra para trabalhar a formalização algébrica da trajetória de tal lançamento.

\title{
2. A ATIVIDADE PROPOSTA
}

Neste trabalho, sugerimos o uso de uma atividade experimental planejada para ser desenvolvida de forma investigativa. A previsão é de que toda a proposta seja realizada em, aproximadamente, 8 horas-aula com objetivo de descobrir, desenvolver, mostrar, validar e formalizar alguns conceitos, definições e propriedades da função quadrática e do lançamento oblíquo.

Esta atividade pode ser aplicada antes de qualquer discussão a respeito de função quadrática e lançamento oblíquo, para que se possa explorar e construir algumas definições e propriedades a partir de conjecturas e discussões com os alunos. Atualmente, esse conteúdo é trabalhado com as turmas de $1^{\circ}$ ano do Ensino Médio, podendo os professores de Matemática e de Física desenvolvê-la em parceria, promovendo assim a articulação entre os conteúdos dessas disciplinas. No entanto, fazse necessário que o professor de Matemática já tenha trabalhado o conceito de função e, dentro desse conceito, tenha abordado detalhadamente a função afim, bem como o esboço de gráfico de funções no plano cartesiano, dando, assim, suporte às discussões a respeito da função e do gráfico que descreverá o movimento observado na presente atividade experimental. Por outro lado, é fundamental que o professor de Física já tenha abordado os conteúdos de Movimento Retilíneo Uniforme (MRU), Movimento 
Retilíneo Uniformemente Variado (MRUV) e Queda Livre, uma vez que as variáveis distância, tempo, velocidade e aceleração serão imprescindíveis para fomentar as discussões relativas à referida atividade.

É importante que os alunos sejam estimulados a participar ativamente da atividade, que apresenta um caráter lúdico. $\mathrm{Na}$ proposta, os alunos individualmente devem construir um minifoguete com materiais simples e de baixo custo. Antes da sua construção, o aluno deve ser desafiado por meio do seguinte problema: como fazer com que o minifoguete atinja o maior alcance horizontal?

\section{Confecção do minifoguete}

Os materiais necessários para confeccionar o minifoguete são: uma caixa de fósforo com palitos, um espetinho de churrasco, um quadrado de papel alumínio com aproximadamente $20 \mathrm{~cm}$ de lado, cola instantânea, como apresentado na Figura 1.

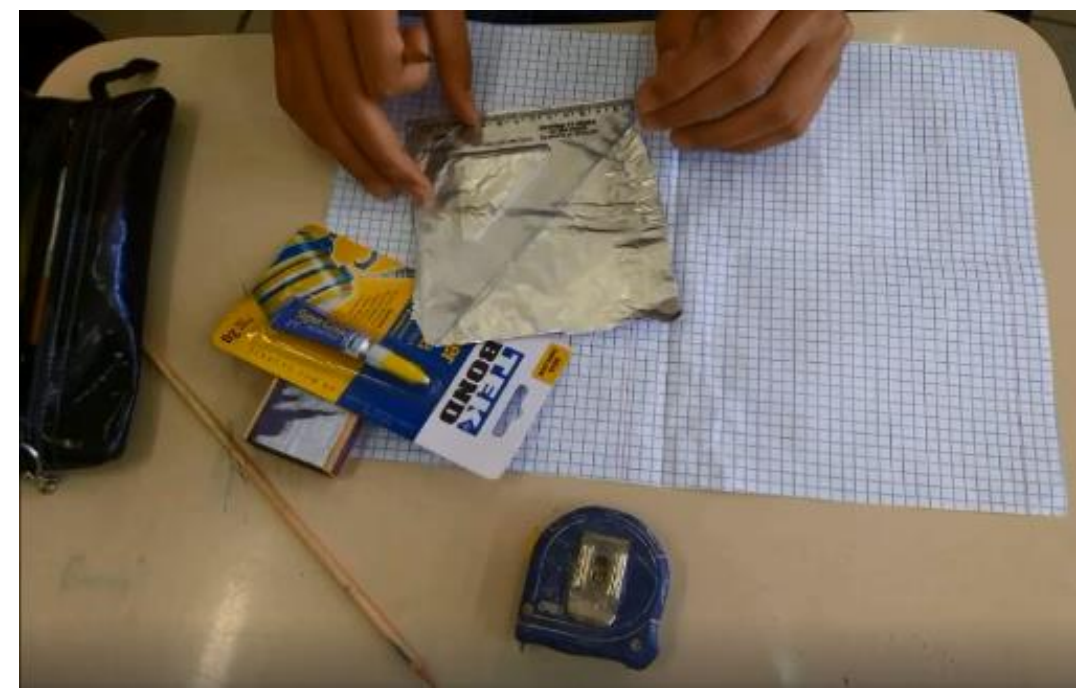

Figura 1 - Construção do minifoguete. Fonte: Autores (2020)

Para efetuar a montagem do minifoguete é necessário recortar um quadrado de papel alumínio com aproximadamente $10 \mathrm{~cm}$ de lado, raspar a pólvora de 5 palitos de fósforo sobre o quadrado de papel alumínio (fazer um montinho) margeando um dos lados e colocar o palito de churrasco sobre o quadrado de papel alumínio com a ponta do palito encostando na pólvora, como ilustra a Figura 2. Em seguida, enrolar o papel alumínio no palito sem deixar a pólvora cair e no final dobrar a ponta, conforme a Figura 3. Por fim, com a sobra de papel alumínio (aproximadamente $10 \mathrm{~cm}$ ), pode-se 
construir as aletas e colar no corpo do minifoguete com a cola instantânea, como na Figura 4.

É importante destacar que os materiais utilizados são de baixo custo e de fácil acesso. Para Santos, Piassi e Ferreira (2004), o uso desse recurso pode facilitar a realização de experimentos, por não necessitar de um laboratório, apontando ainda que "os fenômenos não ficam escondidos pela "caixa preta" de equipamentos que o estudante não sabe exatamente como funciona" (p. 7).

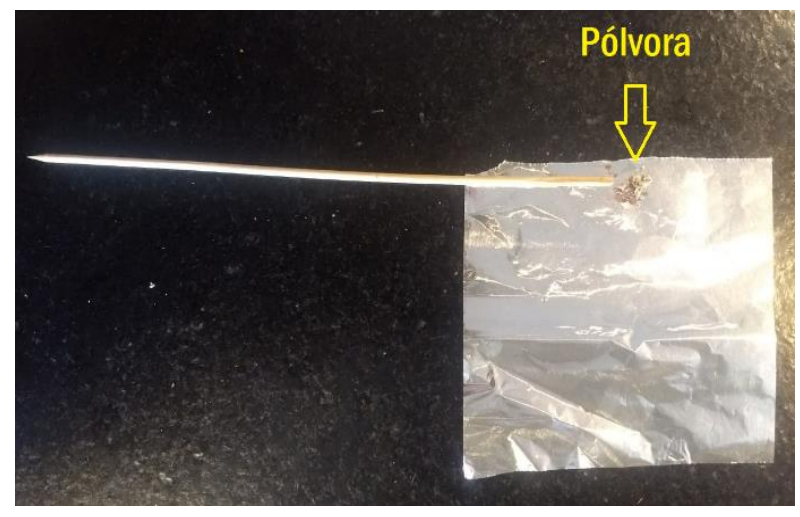

Figura 2 - Disposição da pólvora. Fonte: Autores (2020)

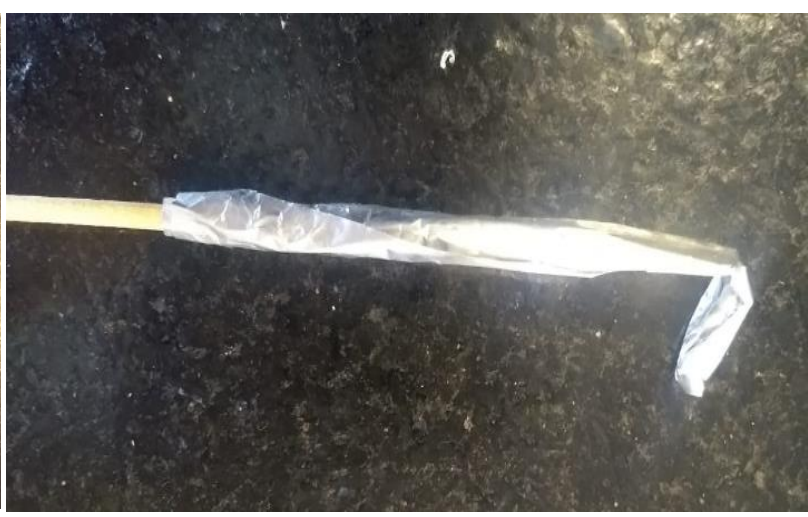

Figura 3 - Corpo do minifoguete. Fonte: Autores (2020)

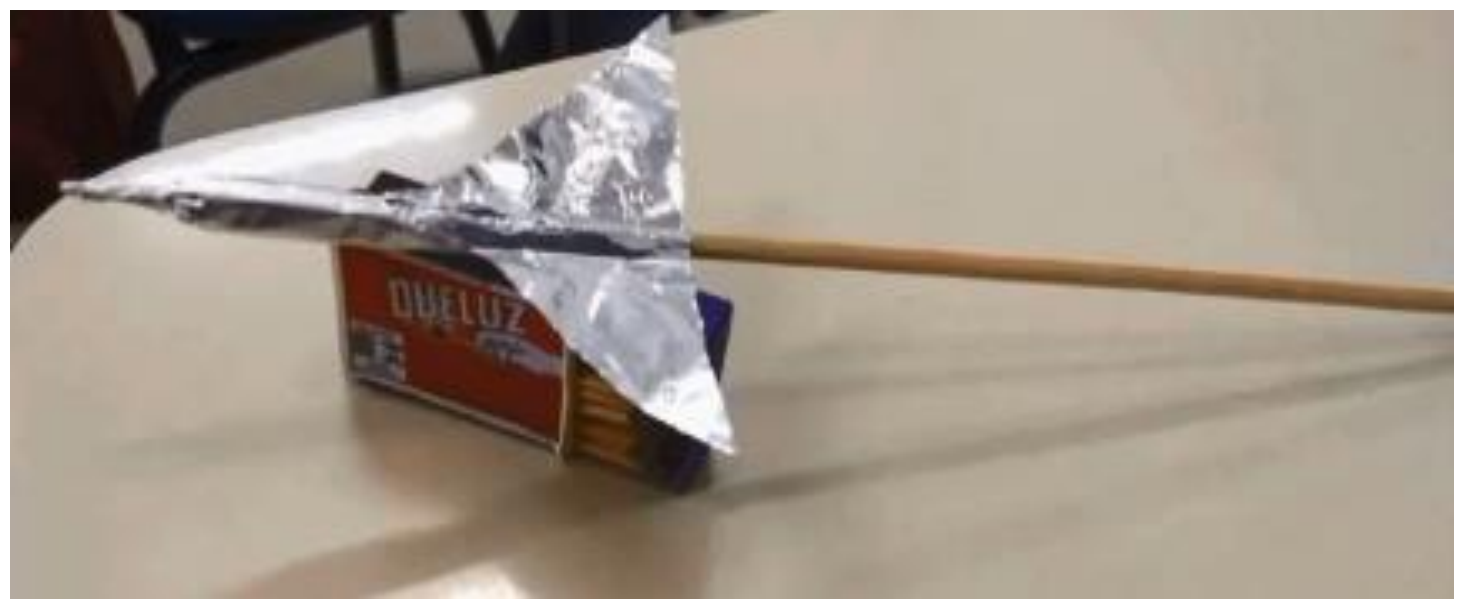

Figura 4 - Construção do minifoguete concluída. Fonte: Autores (2020)

Segundo Guedes (2017), os experimentos elaborados com materiais de baixo custo são recursos simples, baratos e de fácil aquisição, podendo facilitar o processo de ensino e de aprendizagem em sala de aula. No entanto, vale ressaltar que tais materiais devem ser selecionados em função das características dos alunos, do conteúdo, dos objetivos e das estratégias previstas no plano de ensino. 
Além disso, Santos, Piassi e Ferreira (2004) ressaltam que a possibilidade de envolver o aluno na construção do experimento pode propiciar que ele desenvolva

\begin{abstract}
habilidades motoras e de raciocínio lógico, interação com o grupo, trazendo à tona uma série de habilidades, atitudes e capacidades cognoscitivas que de outra forma não se fariam presentes. O caráter lúdico desempenha também um papel fundamental, porque envolve o aluno não somente no âmbito cognitivo, mas também no afetivo e no volitivo. O aprendizado de ciências se dá a partir de problemas relevantes para o estudante, com os quais ele deseja se envolver e que trazem para ele uma satisfação. (SANTOS, PIASSI e FERREIRA, 2004, p. 9)
\end{abstract}

Na perspectiva deste trabalho, é importante ressaltar que o aluno deve ficar à vontade para construir o minifoguete sabendo que ele será lançado com intuito de atingir o maior alcance horizontal possível. Sendo assim, o seu tamanho pode ser variado, podendo ou não conter aletas. Enfim, ele pode modificar o roteiro de construção, com base nas expectativas de melhorar o desempenho no lançamento de acordo com sua experiência ou até mesmo intuição, pois a discussão sobre aerodinâmica ocorrerá posteriormente, durante a análise dos resultados da atividade. Os alunos podem utilizar outros materiais que considerarem convenientes para a realização da atividade, como por exemplo o transferidor para regular a inclinação de lançamento do minifoguete. Porém, essa iniciativa deve partir do próprio aluno, sem que o professor sugira, uma vez que no decorrer das discussões espera-se abordar essa variável como fator importante no desempenho da tarefa.

\title{
Lançamento do minifoguete
}

Após a construção do minifoguete, cada aluno fará seu lançamento. Para tanto, deve-se acender um fósforo e aquecer o ponto do minifoguete onde está concentrada a pólvora, como na Figura 5.

Nesse momento, é importante que o professor não dê orientações com relação a melhor inclinação, pois essa questão também será discutida posteriormente, com base nos resultados obtidos. 


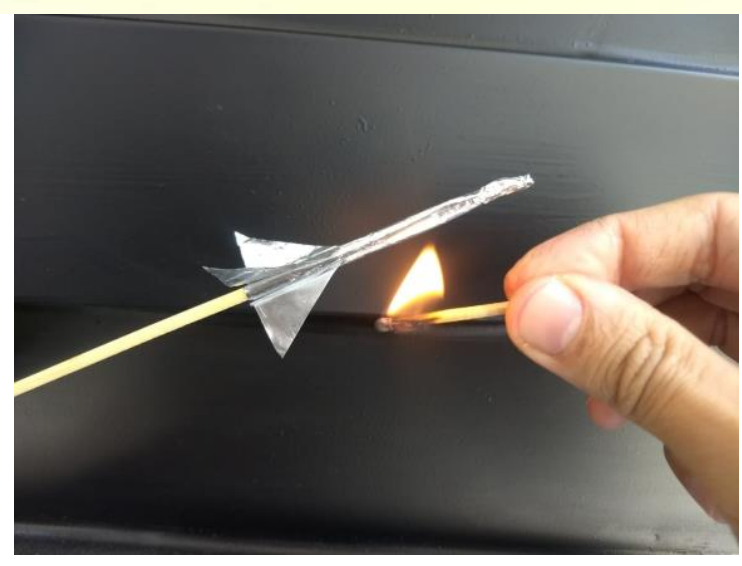

Figura 5 - Lançamento do minifoguete.

Fonte: Autores (2020)
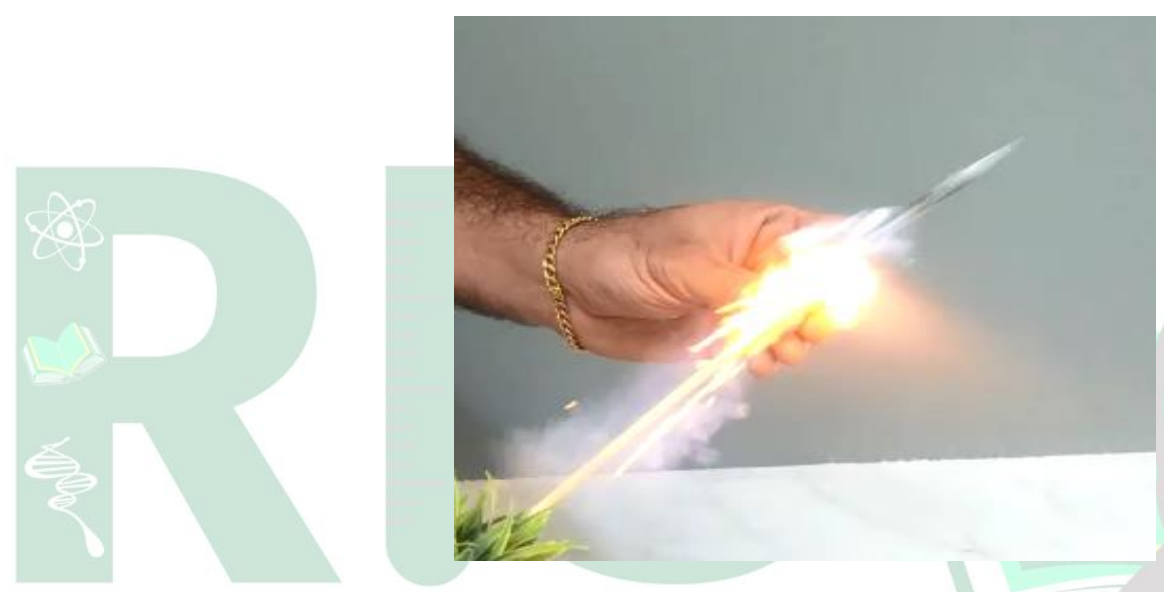

Figura 6 - Momento da explosão. Fonte: Autores (2020)

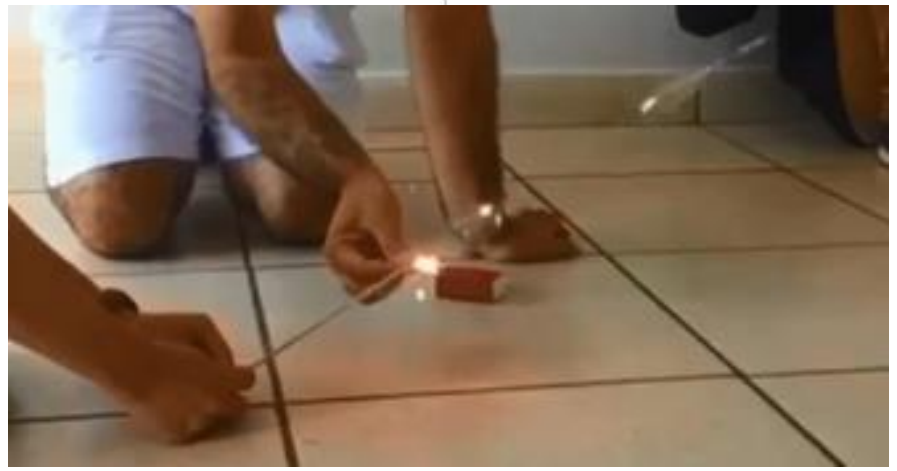

Figura 7 - Minifoguete em voo.

Fonte: Autores (2020)

Para realizar o lançamento, é necessário um espaço que acomode todos alunos e que tenha pelo menos 25 metros de comprimento para o minifoguete transitar, uma vez que esse minifoguete pode ter esse alcance horizontal, de acordo com experiências já 
realizadas. Pode ser em local aberto, mas preferencialmente em um local fechado para que sua trajetória não seja influenciada pelo vento.

Faz-se necessário, também, que os lançamentos sejam filmados, pois como o minifoguete percorre sua trajetória muito rápido, os vídeos irão auxiliar as discussões sobre essa trajetória, uma vez que pode ser retomado em câmera lenta.

Após o lançamento de cada um dos minifoguetes, deve-se medir o alcance horizontal (distância entre o ponto de lançamento e o ponto onde o minifoguete tocou o solo). É relevante lembrar que, em princípio, cada aluno deve desenvolver a atividade com o único objetivo explícito de obter o maior alcance horizontal. Para a discussão, é primordial que todos os fatores que podem influenciar no resultado sejam observados atentamente, por meio da vídeo gravação.

É importante ressaltar que cada minifoguete pode ser reaproveitado, desde que reabastecido com pólvora. Destacamos, ainda, que o manuseio dessa pólvora não oferece risco, considerando que a quantidade é bem pequena e retirada do palito de fósforo. Além disso, por medida se segurança, é recomendável que o próprio professor realize o acendimento do fósforo para efetuar o lançamento do minifoguete.

\section{Discussão}

Após realizar os lançamentos, os alunos devem socializar as observações e levantar hipóteses acerca dos fatores que influenciam o desempenho do minifoguete. Para tanto, o professor pode deixar o ambiente livre sem influenciar na discussão. Espera-se que eles levantem alguns pontos a serem discutidos e, caso isso não ocorra, cabe ao professor fazer questionamentos que suscitem o levantamento desses pontos:

- Em relação à construção do minifoguete, quais os fatores que, provavelmente, interferem no desempenho do minifoguete? (tamanho, massa, aerodinâmica, possuir ou não aletas entre outros). Espera-se que os alunos discutam e concluam que, nesse caso, a aerodinâmica é um fator importante e que as aletas também interferem no movimento, tanto em relação à estabilidade do minifoguete, quanto em relação à capacidade de superar a resistência do ar. Os alunos podem realizar uma pesquisa na internet para facilitar o seu entendimento acerca da construção de minifoguetes.

- Quanto ao lançamento, espera-se que os alunos verifiquem a importância e a influência da inclinação da base de lançamento, bem como que questionem qual o melhor ângulo de lançamento: o que acontece se o ângulo for de $90^{\circ}$ ? E se for de $0^{\circ}$ ? $\mathrm{E}$ 
se estiver entre $0^{\circ}$ e $90^{\circ}$ ? Se o ângulo interfere, qual será o melhor valor para que o alcance seja máximo?

Com intuito de os alunos verificarem que o maior alcance horizontal pode ser obtido por meio do lançamento com ângulo de $45^{\circ}$, o professor pode utilizar uma prática simples usando uma mangueira de água com vazão constante e um transferidor, conforme ilustrado na Figura 8.

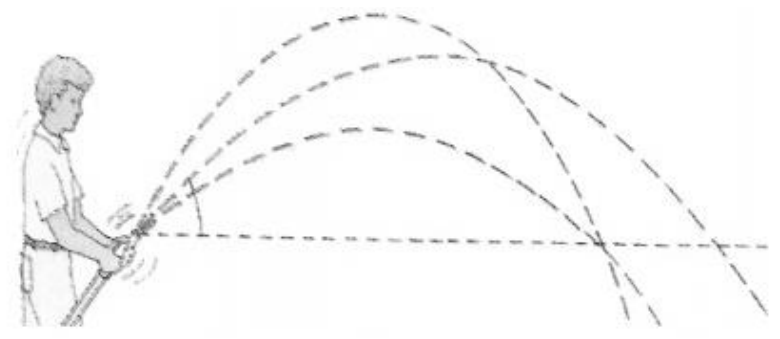

Figura 8 - Modelo de experimento para a verificação da variação do alcance horizontal com a inclinação.

Fonte: Máximo e Alvarenga, 2000, p.202.

Para que não haja desperdício de água, recomenda-se que essa atividade seja feita em um jardim/gramado ou em algum lugar que precisa ser lavado, aproveitando-se, dessa forma, a água usada na atividade.

Com isso, ainda é possível fazer com que os alunos discutam a respeito de inclinações diferentes que possuem o mesmo alcance horizontal e cheguem à conclusão de que os ângulos complementares (soma dos ângulos igual a 90\%) possuem essa característica, como ocorre, por exemplo, com os ângulos: $30^{\circ}$ e $60^{\circ} ; 20^{\circ}$ e $70^{\circ} ; 42^{\circ}$ e $48^{\circ}$ etc. Essa discussão pode tornar o assunto mais concreto, menos abstrato, de modo a propiciar que o aluno visualize e faça a conexão da teoria com a prática.

Posteriormente essa questão pode ser retomada e demonstrada matematicamente, utilizando artifícios algébricos e geométricos, mas, nesse momento, basta a discussão com base nas verificações empíricas.

- Em relação à trajetória, qual a curva que melhor se aproxima da trajetória do minifoguete no espaço? Espera-se que os alunos discutam e descartem a trajetória retilínea (função afim) que já foi estudada anteriormente e que consigam fazer um esboço próximo de uma parábola. Para melhorar a compreensão e aceitação, o professor pode projetar o vídeo do lançamento na lousa em câmera lenta, ir pausando para registrar a localização do minifoguete em cada instante e fazer com que os alunos notem 
a trajetória parabólica, conforme a Figura 9. Uma outra sugestão é utilizar o software GeoGebra para registrar essa trajetória do minifoguete gerada no vídeo.

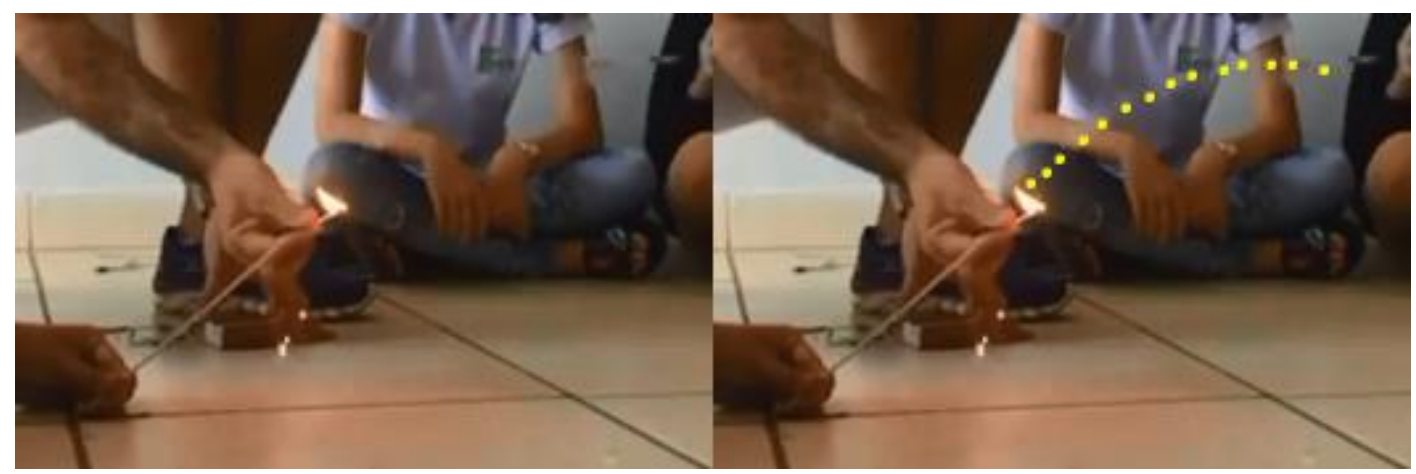

Figura 9 - Trajetória do minifoguete.

Fonte: Autores (2020)

Também há a possibilidade de o professor discutir com os alunos a respeito da parábola e verificar se eles a relacionam com algo além da trajetória no lançamento oblíquo. Nesse contexto, espera-se que eles citem a antena parabólica. O professor pode propor que os alunos realizem uma investigação a respeito desse tema: por que a antena é chamada de parabólica? Por que se faz a antena nesse formato? Quais são suas características? É importante que o professor explique o seu funcionamento, destacando que, "como os sinais que recebemos de rádios ou de luz são muito fracos, quando "captados" pela parábola, ela os concentra em um único ponto, o foco, que os amplia naturalmente, para depois serem refletidos"1, característica essa que torna a antena mais eficiente, como mostra a Figura 10.

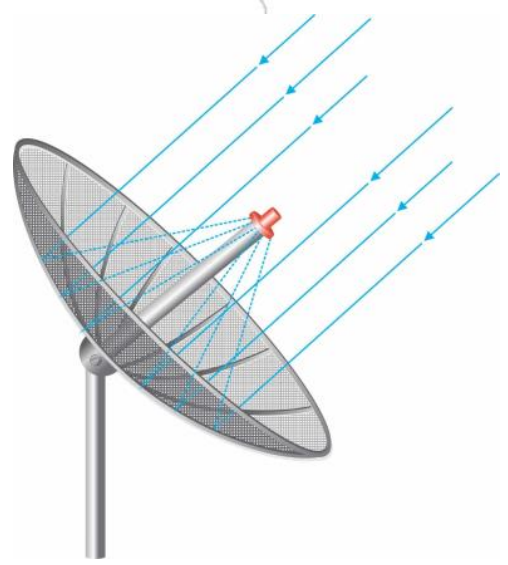

Figura 10 - Esquema de incidência de raios sobre uma antena parabólica. Fonte: Autores (2020)

Como nosso foco é o estudo do lançamento oblíquo, necessitamos, agora, de uma formalização algébrica para essa trajetória. O professor pode formalizar a função

\footnotetext{
${ }^{1}$ Disponível em: <https://www.somatematica.com.br/curiosidades/c94.php >. Acesso em 24 jun. 2020.
} 
quadrática, algébrica e geometricamente, explorando algumas analogias com o que já foi desenvolvido na função afim:

- se a função afim $\left(1^{\circ}\right.$ grau) é do tipo $f(x)=a x+b$ com $a \neq 0$, como será a função quadrática $\left(2^{\circ}\right.$ grau $)$ ?

- com auxílio do software GeoGebra ${ }^{2}$ construir o gráfico de uma função quadrática do tipo $f(x)=a x^{2}+b x+c$, com $a \neq 0$, e verificar o formato da curva para diferentes valores dos coeficientes $a, b$ e $c$, deixando-os como valores deslizantes, como na Figura 11.

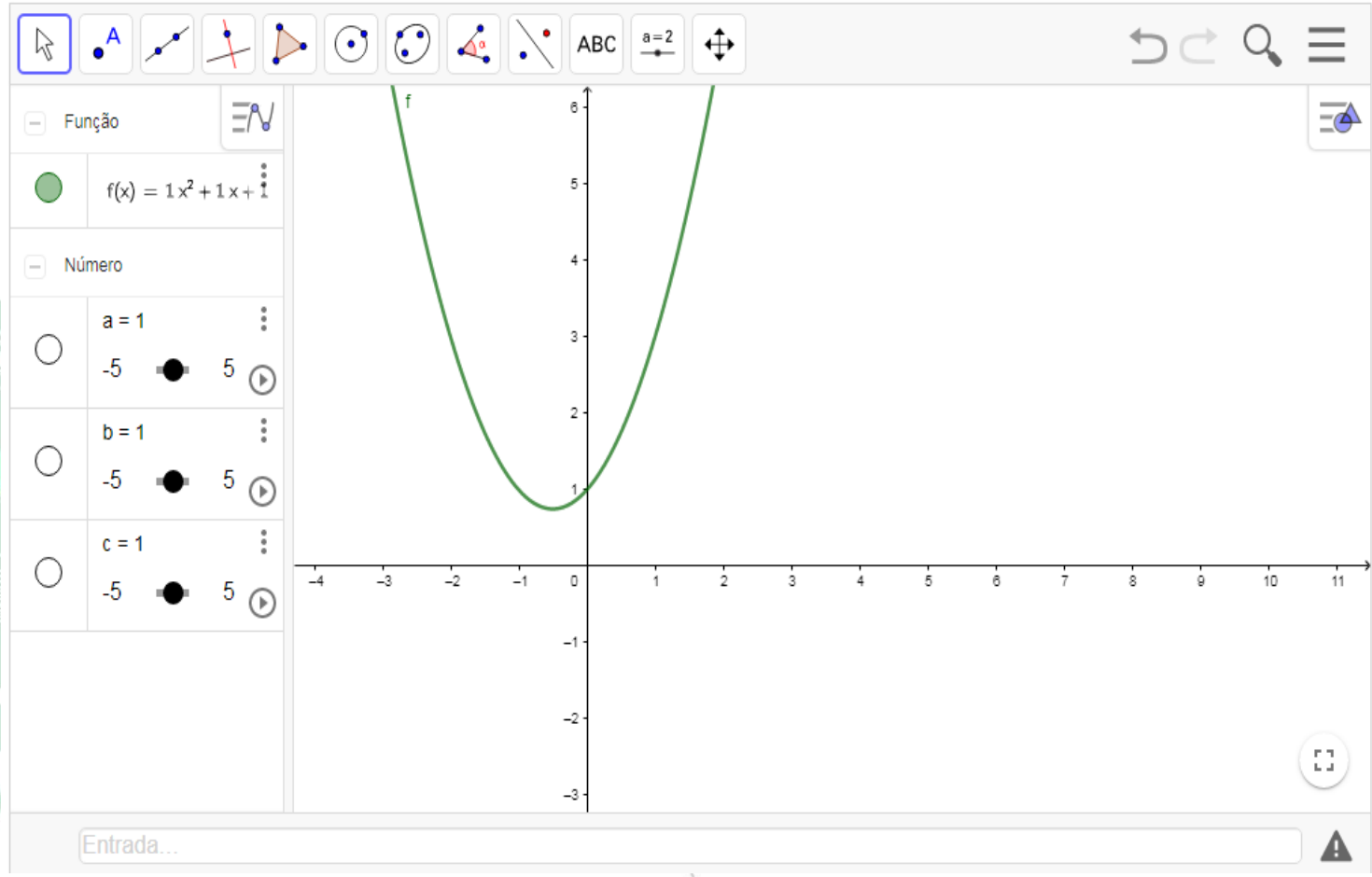

Figura 11 - Construção e análise dos coeficientes da parábola no GeoGebra de incidência de raios sobre uma antena parabólica.

Fonte: Autores (2020)

- de acordo com a manipulação dos valores dos coeficientes $a, b$ e $c$, qual a interferência de cada um desses coeficientes no gráfico?

- quais os principais pontos de definição de uma parábola e como calculá-los?

Após essas discussões, espera-se que os alunos notem a semelhança entre a trajetória do minifoguete e o esboço da parábola, para que, dessa forma, percebam que

${ }^{2} \mathrm{O}$ GeoGebra é um aplicativo de matemática dinâmica que combina conceitos de geometria e álgebra em uma única interface. Com isso, o programa reúne as ferramentas tradicionais de geometria com outras mais adequadas à álgebra e ao cálculo. Sua distribuição é livre, nos termos da GNU General Public License, e é escrito em linguagem Java, o que lhe permite estar disponível em várias plataformas. Pode ser baixado gratuitamente no link https://www.geogebra.org/?lang=pt. 
essa trajetória pode ser modelada por uma função quadrática que, restringindo-se ao plano cartesiano, relaciona a posição horizontal (valor no eixo das abcissas - eixo x) com a posição vertical (valor no eixo das ordenadas - eixo y), ou seja, relaciona a posição horizontal com a altura do minifoguete durante a trajetória.

Concomitantemente, o professor de física, em suas aulas, pode retomar alguns conceitos abordados anteriormente, ressaltando que, no lançamento oblíquo, tem-se Movimento Uniforme, na direção horizontal, e Movimento Uniformemente Variado com aceleração igual a da gravidade, na direção vertical. Nesse contexto, esse professor pode abordar a função quadrática $S=S_{0}+v_{0} t+a t^{2} / 2$ usando as gravações realizadas no lançamento do minifoguete.

É importante salientar que, como essa função quadrática tem como gráfico uma parábola, muitos alunos ao visualizarem essa parábola podem confundi-la com a própria trajetória do minifoguete. Por isso, é fundamental que o professor ressalte que essa parábola não representa a trajetória de um corpo, destacando que o percurso do minifoguete é parabólico, mas não é representado por essa função que relaciona a altura em função do tempo, mas sim por uma função quadrática que relaciona o deslocamento vertical (altura) em função do deslocamento horizontal.

\section{CONSIDERAÇÕES FINAIS}

O caráter lúdico da presente proposta de atividade experimental investigativa pode despertar o interesse do aluno e facilitar a sua compreensão acerca do conteúdo abordado (função quadrática e lançamento oblíquo). Ademais, a confecção do minifoguete é rápida, podendo ser concluída em uma aula de 50 minutos, os materiais utilizados são acessíveis, a atividade é fácil de ser realizada e as medidas são simples de serem obtidas, de forma que a realização dessa atividade é apropriada ao tempo de aula.

O experimento em questão permite, também, a validação de algumas propriedades e conceitos, o que pode levar o aluno a perceber a teoria por meio da visualização do experimento, além de promover o desenvolvimento e a articulação dos conceitos, relacionando-os com o cotidiano. Possibilita, ainda, por meio de observações e discussões, a formalização matemática do lançamento oblíquo, buscando mostrar a teoria que, muitas vezes, parece abstrata. Além disso, permite que o aluno levante hipóteses, considere alguns parâmetros que, normalmente, são desprezados na teoria, tal 
como a resistência do ar, e identifique ideias inadequadas associadas ao senso comum, tal como a confusão entre as funções quadráticas citadas anteriormente (deslocamento vertical em função do tempo e deslocamento vertical em função do deslocamento horizontal).

Por fim, a atividade proposta pode desenvolver no aluno a capacidade de participar da construção de seu próprio conhecimento, ou, mais especificamente, de formular teorias ao abordar situações e acontecimentos reais.

\section{REFERÊNCIAS}

ALMEIDA, M. E. A formação de recursos humanos em informática educativa propicia a mudança de postura do professor? In: VALENTE, J. A. O professor no Ambiente Logo: formação e atuação. Campinas, SP: UNICAMP/NIED, 1996.

BATISTA, R. F. M.; SILVA C. C. A abordagem histórico-investigativa no ensino de Ciências. Estudos Avançados, São Paulo, SP, vol.32, n.94, set./dez. 2018.

BORGES, A. T. Novos rumos para o laboratório escolar de ciências. Caderno Brasileiro de Ensino de Física, Florianópolis, SC, v.19, n.3, p.291-313, 2002.

BRANDÃO, C. L. F.; LANDIM, E. A. O Ensino da Função Afim com o Auxílio do Software Geogebra. In: XI ENCONTRO NACIONAL DE EDUCAÇÃO MATEMÁTICA, 2013, Curitiba, PR. Anais do XI Encontro Nacional de Educação Matemática, Curitiba, 2013, p.1-12.

BRASIL. Ministério da Educação. Secretaria de Educação Básica, Secretaria de Educação Continuada, Alfabetização, Diversidade e Inclusão; Secretaria de Educação Profissional e Tecnológica. Base Nacional Comum Curricular. 2017. Disponível em: $<$ http://basenacionalcomum.mec.gov.br/wp-content/uploads/2018/02/bncc-20dezsite.pdf $>$.

FORNAZIERE, A. A.; LÜBECK, M. O uso do software geogebra como ferramenta didático-pedagógica para o ensino da geometria plana: uma possibilidade de sair dos trilhos e se aventurar por novos caminhos no estudo dos polígonos. In: PARANÁ. Secretaria de Estado da Educação. Os desafios da escola pública paranaense na perspectiva do professor PDE. Foz do Iguaçu, PR: UNIOESTE/SEED, Cadernos PDE, ISBN 978-85-8015-076-6, v.1, 2013.

GUEDES, L. D. S. Experimentos com materiais alternativos: sugestões para dinamizar a aprendizagem de eletromagnetismo, 2017. Dissertação de mestrado (Mestrado Profissional em Ensino de Física) - Universidade Federal de Goiás, Polo de Catalão, 2017.

GRAVINA, M. A. Geometria Dinâmica: Uma Nova Abordagem para o Aprendizado da Geometria. In: VII CONGRESSO BRASILEIRO DE INFORMÁTICA NA EDUCAÇÃO, 1996, Belo Horizonte, MG. Anais do VII Simpósio Brasileiro de Informática na Educação, Belo Horizonte, 1996, p.1-13.

LABURÚ, C. E. Seleção de Experimentos de Física no Ensino Médio: Uma investigação a partir da fala dos professores. Investigações em Ensino de Ciências, Porto Alegre, v.10, n.2, p.1-19, 2005. 
LORENZATO, S. Laboratório de ensino de matemática e materiais didáticos manipuláveis. In: LORENZATO, Sérgio. Laboratório de Ensino de Matemática na formação de professores. Campinas, SP: Autores Associados, 2006. p.3-38

MÁXIMO, A.; ALVARENGA, B. Curso de Física. $5^{\text {a }}$ ed., São Paulo: Scipione, 2000.

ORZECHOWSKI, T. P; LOPES, M. R. C. M. O uso do geogebra na construção de conceitos de geometria plana e espacial. In: PARANÁ. Secretaria de Estado da Educação. Os desafios da escola pública paranaense na perspectiva do professor PDE. Curitiba, PR: UNIOESTE/SEED, Cadernos PDE, ISBN 978-85-8015-093-3, v.1, 2016.

SANTOS, E. I; PIASSI, L. P. C; FERREIRA, N. C. Atividades experimentais de baixo custo como estratégia de construção da autonomia de professores de física: uma experiência em formação continuada. In: IX ENCONTRO DE PESQUISA EM ENSINO DE FÍSICA, 2004, Jaboticatubas, MG. Anais do IX Encontro de Pesquisa em Ensino de Física, Jaboticatubas, MG: Sociedade Brasileira de Física, 2004, p.1-18.

SANTOS, T. A matofobia no ámbito educativo e as dimensões para seu estudo. In: XIII CONGRESSO NACIONAL DE EDUCAÇÃO - EDUCERE, 2017, Curitiba, PR. Anais do XIII Congresso Nacional de Educação, Curitiba, 2017, p.7458-7466. Disponível em:〈https://educere.bruc.com.br/arquivo/pdf2017/24585_11936.pdf〉. Acesso em: 08 Out. 2019.

SARMENTO, A. K. C. A utilização dos materiais manipulativos nas aulas de matemática. In: VI ENCONTRO DE PESQUISA EM EDUCAÇÃO, 2010, Teresina, PI. Anais do VI Encontro de Pesquisa em Educação da UFPI, Teresina: Universidade Federal do Piauí, 2010, p.1-12.

TOLEDO, E. J. L.; FERREIRA, L. H. A atividade investigativa na elaboração e análise de experimentos didáticos. Revista Brasileira de Ensino de Ciência e Tecnologia, v.9, n.2, p.108-130, mai./ago. 2016. 